\title{
Review \\ Epithelial to mesenchymal transition and breast cancer
}

\section{Eva Tomaskovic-Crook ${ }^{1}$, Erik W Thompson ${ }^{2}$ and Jean Paul Thiery ${ }^{1}$}

\author{
${ }^{1}$ Institute of Molecular and Cell Biology, 61 Biopolis Drive, Proteos, Singapore 138673, Singapore \\ ${ }^{2}$ St Vincent's Institute and University of Melbourne Department of Surgery, St Vincent's Hospital, Fitzroy, Melbourne, Victoria 3065, Australia
}

Corresponding author: Jean Paul Thiery, jpthiery@imcb.a-star.edu.sg

Published: 9 November 2009

This article is online at $h t t p: / /$ breast-cancer-research.com/content/11/6/213

(c) 2009 BioMed Central Ltd
Breast Cancer Research 2009, 11:213 (doi:10.1186/bcr2416)

existence of EMT changes in clinical breast cancer places EMT at the center of malignancy. While presently there are no reports of mutations in important EMT regulators driving malignancy or disease progression, ensuing studies may clarify their involvement. Similarly, the EMT process is only starting to be specifically targeted for therapeutic benefit, although several current therapeutic targets are implicated in driving EMT. We anticipate that the growing acceptance of EMT will bring such translational advances in the coming years.

Regulation of epithelial cell plasticity during EMT is increasingly implicated in the progression of carcinoma. Epithelial cells that undergo EMT lose their epithelial cell characteristics to acquire a mesenchymal phenotype and become migratory and invasive. Thus, EMT is characterized by cellular and molecular changes that include: the loss of cell-cell adhesion and apical-basal polarity involving Ecadherin (CDH1) in adherens junctions, occludins (OCLN) and claudins (CLDN) in tight junctions, and desmoplakin (DSP) in desmosomes; downregulation of epithelial cytokeratins (KRT8, KRT18, and KRT19); upregulation of mesenchymal proteins vimentin (VIM) and, in some cases, alphasmooth muscle actin (ACTA2); reorganization of cytoskeleton to acquire more spindle-like morphology; increased motility and invasiveness involving dynamic actin microfilament networks; and increased resistance to apoptosis. During carcinoma progression, epithelial cells detach from the primary tumor, adhere to and invade the surrounding stroma, intravasate into blood vessels, and disseminate to distant tissues and organs where they extravasate and can lead to secondary tumors. The processes required for metastasis of epithelial cells from primary tumors closely resembles that of cells undergoing EMT followed by mesenchymal to epithelial transition at the site of arrest [1-3].

ACTA2 = alpha-smooth muscle actin; $\mathrm{BCSC}=$ breast cancer stem cell; CTC $=$ circulating tumor cell; EMT = epithelial to mesenchymal transition; $\mathrm{ERBB2}=$ human epidermal growth factor receptor 2; FOX = forkhead box protein; FSP = fibroblast-specific protein; KRT $=$ keratin; miRNA $=$ microRNA; MMTV = mouse mammary tumor virus; PIK3CA = phosphoinositide-3-kinase, catalytic, alpha polypeptide; PyMT = polyoma middle T antigen; RB1 = retinoblastoma 1; SNAI = zinc finger protein snail; SPARC = secreted acidic cysteine rich glycoprotein; TGFbeta $=$ transforming growth factor beta; WAP = whey acidic protein; ZEB = zinc finger E-box-binding homeobox. 


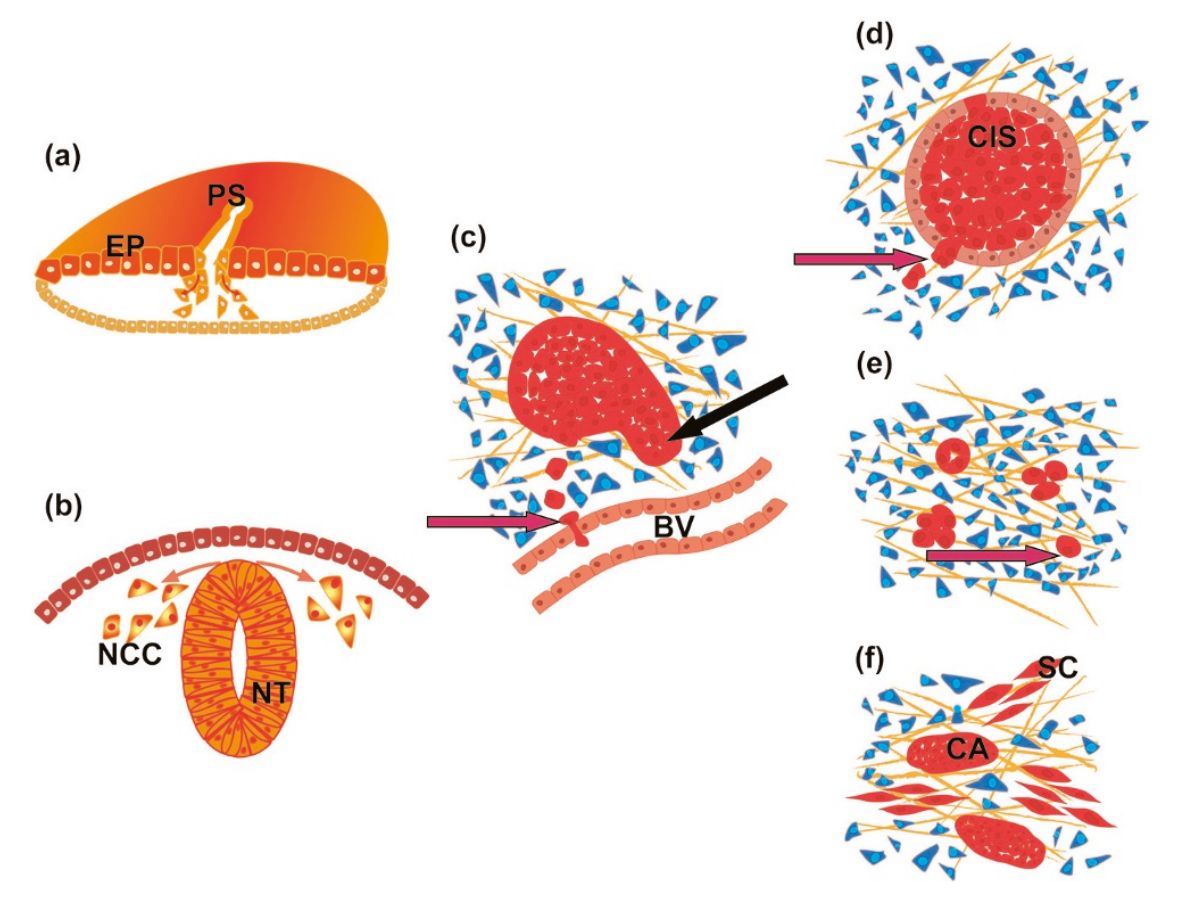

Epithelial to mesenchymal transition processes in development and cancer. (a) Epithelial to mesenchymal transition (EMT) in chicken embryo at the gastrulation stage. Epiblast cells (EP) delaminate at the primitive streak (PS) and undergo extensive migration before giving rise to different mesodermal derivatives. (b) EMT in the ontogeny of the neural crest. Neural crest cells (NCC) delaminate from the dorsal neural tube (NT; trunk level in chicken embryos). (c) EMT in murine mammary carcinoma tumors either in transgenic or fat pad orthotopic tumor implantation models. EMT is one of the mechanisms allowing solitary cells to reach blood vessels (BV) and intravasate (purple arrow). The involvement of macrophages in the invasion and intravasation of solitary carcinoma cells is not shown in the schematic diagram. Carcinoma can also invade the stroma (black arrow) through collective cell migration [87]. (d) EMT in breast ductal carcinoma in situ (CIS) at the microinvasive stage. Arrow points to cells delaminating from the in situ carcinoma mass. (e) EMT in invasive ductal carcinoma. High grade invasive carcinoma contains single cells among cell clusters. Some cells can also intravasate blood vessels (not shown) and form a transient interaction with macrophages [82]. An EMT signature is found to be mostly associated with the basal subtype [28]. (f) EMT in sarcomatoid carcinoma. Sarcoma-like malignant cells (SC) are closely apposed to carcinoma islands (CA). It is not known whether carcinoma cells can reversibly acquire the sarcoma-like phenotype; however, both subtypes share genetic alterations and the sarcoma subtype exhibits an EMT signature [88]. Blue cells in the schematic diagrams represent stromal cells.

\section{Histopathological characterization of breast cancer}

Greater than $95 \%$ of breast cancers are of epithelial origin. Although there are several histological types, primary histopathological analysis of breast carcinoma establishes whether the lesion is in situ carcinoma (confined to the glandular component of the breast and distinguished from benign breast diseases in part by a discontinuous outer myoepithelial cell layer, and cytoarchitecture) or invasive carcinoma, which can be either ductal (located at the junction between the terminal duct and the lobule) or lobular (within the breast lobules).

Histopathological grading of the invasive portion of the breast carcinoma (also known as the histoprognostic index) is a powerful indicator of prognosis in breast cancer. The index is based on the analysis of the following three criteria, with each element given a rank of 1 to 3: evaluation of architecture/ tubule formation, measuring the degree of differentiation, with
1 corresponding to more than $75 \%$ glandular structures, 2 between 10 and 75\%, and 3 below 10\%; anisokaryosis, measuring the state and size of the nucleus, with 3 corresponding to the largest and most irregular nuclei; and proliferation assessed by the mitotic index, given the value of 1 for less than 10 mitoses per 10 microscopic fields (400x magnification), 2 for 11 to 20 mitoses, and 3 for greater than 20 mitoses. In the Nottingham grading system [4], a grade of I is given for a combined score of 3 to 5 , II for 6 to 7 , and III for 8 to 9 . That this index is now preferred over the classical Scarff Bloom Richardson grading system is a strong indicator of tumor progression reflecting in part the extent of EMT in the carcinoma component of the tumor, since EMT will strongly influence the architecture/tubule component.

Breast carcinoma displays histological heterogeneity; epithelial cell plasticity can generate distinct cellular subpopulations that contribute to intratumoral heterogeneity. However, most tumors display a dominant phenotype that enables 
classification of the tumor. Several subtypes of breast carcinoma have been identified with different clinical outcomes and response to therapy. Methods to classify breast tumors have included histopathology, molecular and clinical pathology, genetic analysis and gene expression profiling. Histological and molecular classification of breast cancer describes at least four different phenotypes: the normal-like phenotype has an expression profile that is similar to non-cancerous breast tissue; the luminal phenotype generally includes tumors that are estrogen receptor-positive, and express the epithelial makers E-cadherin and KRT8, KRT18, and KRT19; the estrogen receptor-negative tumor phenotype overexpresses either the human epidermal growth factor receptor 2 (ERBB2), or markers characteristic of myoepithelium of the normal mammary gland, including epidermal growth factor receptor, p63, and basal cytokeratins KRT14, KRT5/6 and KRT17; these tumors are designated basal-like [5-7]. The classification of breast tumors is an important determinant for prognosis and responsiveness to therapy. The ERBB2 and basal-like phenotypes exhibit unfavorable prognosis and resistance to therapy, although the ERBB2 subgroup is well treated with targeted therapy such as Herceptin, and, paradoxically, the basal-like tumors show higher initial responses to neoadjuvant chemotherapies $[8,9]$. In addition, the basal-like tumors show preferential relapse to brain and lung [10-12].

\section{Molecular mechanisms of epithelial to mesenchymal transition}

The process of EMT requires coordination of a complex network of extracellular and intracellular signals involving factors for initiation and feedback mechanisms for a continuum of changes that occur within cells during transition from a less epithelial to more mesenchymal phenotype. EMT can be induced during in vitro cell culture under the influence of extracellular matrix components and growth factors, such as transforming growth factor beta (TGFbeta), scatter factor/hepatocyte growth factor, fibroblast growth factors, epithelial growth factor family members and insulin-like growth factors 1 and 2 [2]. Signal transduction pathways such as Wnt, Hedgehog, Notch and integrin signaling can also coordinate EMT programs. A number of transcription factors induce EMT through transcriptional control of E-cadherin, including SNAl1 (zinc finger protein snail 1), SNAI2, ZEB1 (zinc finger E-box-binding homeobox 1), ZEB2, TWIST, FOXC1 (forkhead box protein 1), FOXC2, TCF3 (transcription factor 3 - also known as E47), and GSC (homeobox protein goosecoid) [13].

\section{Evidence of epithelial to mesenchymal transition in breast cancer Comparisons between evidence from cell lines and breast tumors}

Histopathological characterization of breast carcinoma is essential to correlate tumor phenotypes with molecular alterations described in vitro or in animal models of breast carcinoma. Much of the evidence for a possible role of EMT in progression of breast cancer has arisen from studies of in vitro culture of epithelial cell lines. However, EMT has largely been described as a cell culture phenomenon without direct clinical evidence or clear molecular markers in breast carcinoma [14]. The culture of epithelial cells under specific culture conditions can transform epithelial cells into fibroblast-like cells, whereby cells cannot achieve epithelial type polarity and the culture conditions facilitate dispersal. Another inherent problem is an absence of markers for EMT as faithful indicators of the degree to which epithelial cells are engaged in EMT. Cytokeratin markers commonly used as pathological identifiers of carcinoma are often downregulated, and an upregulation of vimentin expression in epithelial cells undergoing EMT is difficult to distinguish from the surrounding stromal cells [15].

\section{Histological correlates associated with EMT in breast cancer}

Microarray gene expression profiles of patients with breast cancer suggest that the activation of EMT pathways is correlated with histological grade. Specifically, upregulation of genes involved in EMT is associated with poorly differentiated tumors relative to low-grade tumors [16]. Several factors have been shown to play a role. The metastatic process is more frequent in patients where cytokeratinpositive disseminated tumor cells are detected in the bone marrow [17]. In addition, there is a significant correlation between the loss of syndecan-1 expression with high grade tumors and poor relapse-free survival in patients with invasive ductal breast carcinoma [18]. Laminin 5, expressed in metaplastic and other basal-like carcinoma, induces aggressive properties in cancer cells, including motility, invasion, and EMT [19]. Decreased retinoblastoma 1 (RB1) expression is also associated with high-grade breast adenocarcinoma. There is a possible relationship between the loss of RB1 function and a less differentiated state, increased proliferation, and high metastatic potential in patients, which has been tested using in vitro models of growth factor- and cytokineinduced EMT in MCF10A human mammary epithelial cells [20]. Furthermore, RB1 controls expression of E-cadherin; knockdown of RB1 by small interfering RNA in MCF7 breast cancer cells disrupts E-cadherin-mediated cell-cell adhesion and induces a mesenchymal-like phenotype [20]. Another molecule that has appeared as a histological correlate of grade and EMT is Stromelysin-3 (MMP11) [21]. Stromelysin3 enhanced tumorigenesis in the highly differentiated 'early stage' breast cancer cell lines, as well as breast cancer cell lines that have already undergone EMT [22]. Elevated expression of TWIST in breast tumor samples from patients correlates strongly with high-grade invasive carcinoma and with chromosome instability to promote an EMT-like transition that is pivotal for the transformation into an aggressive breast cancer phenotype [23], consistent with its role in driving mouse mammary carcinoma cell metastasis [24]. SNAl1 expression is inversely correlated with the degree of tumor 
differentiation and is expressed in infiltrating ductal carcinoma presenting with lymph node metastases [25]. Further evidence of the role of SNAI1 as a marker of metastatic potential is demonstrated by high levels of SNAI1 correlated with increased risk of breast cancer relapse and local recurrence in a transgenic mouse model [26]. Histopathologic change associated with EMT is exhibited in primary breast carcinoma and is correlated with a higher tumor grade, high mitotic index, and negative estrogen/progesteronereceptor status [27].

Unsupervised clustering of microarray-based immunohistochemisty profiles of tissues from patients with invasive breast cancer and carcinosarcoma has shown an EMT signature [28]. Furthermore, markers commonly associated with EMT (upregulation of $\mathrm{N}$-cadherin, cadherin-11 and the mesenchymal markers vimentin and ACTA2, overexpression of the extracellular matrix remodeling and invasion proteins SPARC (secreted acidic cysteine rich glycoprotein), laminin and fascin, and downregulation of the epithelial markers E-cadherin and cytokeratins) segregate with basal-like breast tumors in patients. Interestingly, gene expression profiles of MCF10A cells grown under low cell density conditions to simulate EMT initiation in fibroblastic cells display a differentiation program characteristic of EMT, which includes upregulation of SNAI2 and vimentin, cytoskeletal reorganization, switching of $\mathrm{E}$ cadherin to $\mathrm{N}$-cadherin expression, and cytosolic relocalization of catenins. These cells also display a basal-like phenotype [28]. A 'poor prognosis' signature from lung-metastatic breast cancer cells links Wnt pathways with EMT [29].

\section{Genomic and transcriptomic correlates associated with EMT in breast cancer}

A recent integrated genomic-proteomic approach using comparative genomic, transcription profiling, reverse-phase protein array analysis and sequencing for common breast cancer mutations has shown that metaplastic breast cancers, which are characterized by lineage plasticity, display unique DNA copy number aberrations, increased frequency of PIK3CA (phosphoinositide-3-kinase, catalytic, alpha polypeptide) mutations, higher phosphorylation of phosphoinositide-3 kinase/AKT pathway phosphorylation sites and altered transcriptional profiles compared to common breast cancers [30]. Comparative genotypic analysis of microsatellite markers has also been used in an attempt to reveal the clonal origins of epithelial and mesenchymal components of tumors. Approximately $11 \%$ of tumors share a significant number of loss of heterozygosity markers in the carcinoma and adjacent stroma [31].

The process of EMT has been implicated in the progression of carcinoma in situ to invasive breast cancer [32]. In gene expression profiling studies, ductal carcinoma in situ and invasive breast carcinoma of the same grade cluster together, suggesting a common origin [33], and share similar genomic alterations [34]. In addition, in primary tumor consisting of evidence of three types of invasion - ductal, squamous, and sarcomatous - loss of cytokeratin and acquisition of vimentin and ACTA2 in the sarcomatous component suggests EMT had occurred in the progression to metaplastic breast carcinoma. Evidence of EMT in the progression of metaplastic breast carcinoma was also shown in nodal metastasis of the ductal component of metaplastic breast carcinoma [35].

\section{Molecular mechanisms implicated in EMT and shown in breast cancer}

Amongst other factors, the inducers of EMT, ZEB and SNAI downregulate the expression and functional organization of core polarity complexes. Upregulation of ZEB1 promotes tumor cell dedifferentiation by repressing master regulators of epithelial polarity as shown in invasive ductal and lobular breast carcinoma [36]. Expression of EMT-related genes, including the EMT-inducing transcription factor FOXC2, has been associated with the basal-like subtype of basal breast cancer [28,37]. Basal-like tumors show high expression of EMT-induced markers (vimentin, ACTA2, N-cadherin, cadherin-11), SPARC, laminin and fascin, low expression of E-cadherin [28], and poor prognosis due to increased ability to form metastases in distal organs compared to other subtypes of invasive breast carcinoma $[5,6]$. Interestingly, although Korsching and colleagues challenged the notion that the expression of vimentin in breast carcinoma is due to EMT [38], this has not been supported by studies that associate markers of EMT in breast carcinoma of the basal phenotype [28,39-41]. Furthermore, although lobular carcinomas have been suggested to display characteristics of EMT due to their downregulation of E-cadherin and pattern of invasion, these cancers do not express other additional markers of EMT [28]. TGFbeta induces similar EMT phenotypes in NMuMG and BRI-JM01 cell line models of EMT; however, the proteomes of the two cell lines show only minimal overlap. The differences may arise from the two cell lines using different mechanisms to achieve an EMT transition [42]. More recently, it has been shown that TGFbeta can induce EMT, although activated Ras in coordination with TGFbeta-induced EMT is required to confer the tumorigenic and invasive potential [43]. Interestingly, glycogen synthase kinase 3 beta, which has previously been shown to regulate nuclear localization of SNAI2 [44], is correlated with tumor grade in patients with invasive ductal carcinoma, suggesting a role for EMT mediators in tumor progression [45].

\section{MicroRNA regulation of epithelial to mesenchymal transition in breast carcinoma}

MicroRNAs (miRNAs) have recently been described as crucial regulators of EMT and metastasis. The miR-200 family, which suppresses EMT drivers ZEB1 and ZEB2, is selectively expressed in the sarcomatous component of metaplastic breast cancers [46]. In addition, miR-10b is highly expressed in metastatic breast cancer cells and promotes tumor invasion and migration in vitro. miR-10b expression, which is regulated by TWIST, correlates with clinical progression in primary 
breast carcinomas [47]. Upregulation of miR-29a is also seen in a mesenchymal, metastatic RasXT mammary cell line compared to epithelial EpRas cells. Furthermore, overexpression of miR-29a suppressed the expression of tristetraprolin, a regulator of epithelial polarity and metastasis, and led to EMT and metastasis in cooperation with oncogenic Ras signaling. These findings correlate with observations in samples from breast cancer patients that show enhanced miR-29a and reduced tristetraprolin levels [48]. These powerful programmatic regulators are poised to become important predictive/prognostic markers.

\section{Epithelial to mesenchymal transition in mouse models of breast carcinoma}

Mouse mammary tumor models are a valuable tool for direct visualization of EMT during cancer progression in vivo. A number of viral and cellular oncogene-driven mammary tumor models have been developed, including the whey acidic protein (WAP)-myc [49], mouse mammary tumor virus (MMTV)-neu [50] and MMTV-polyoma middle $T$ antigen (MMTV-PyMT) [51] mouse models of breast cancer. Animal models have an advantage over in vitro cell lines and studies of breast cancer tumors from patients because of their ability to recapitulate the tumor-associated stromal environment and allow mapping of epithelial and stromal cell fates. Each animal model has unique molecular, cellular and clinical features that allow evaluation of different aspects representing some of the heterogeneity seen in breast cancer. MMTV-neu mammary tumors form solid tumors with little stroma and are locally invasive [52], while MMTV-PyMT tumors have more stroma [53]. The MMTV-PYMT mammary tumor model develops mammary spindle cell tumors that display EMT characteristics, whereas spindle cell tumors are not common in human breast cancer [54]. WAP-myc tumors have abundant stromal cells that surround the invasive tumors [31]. Comparing fibroblast-specific protein (FSP; also known as S100A4)-cre as a reporter of cells engaged in EMT and WAP-cre as a reporter of the epithelial origin, it was clearly shown that EMT was most extensive in WAP-myc transgenic mice. They concluded, however, that Myc required collaboration from additional molecules to induce EMT, and furthermore, overt evidence of EMT in both the mouse models and human tumors was not required for metastasis [31]. Earlier transgenic mouse studies showed FSP-green fluorescent proteinlabeled $\mathrm{Neu}$ mammary carcinoma cells escaping the primary tumor to re-epithelialize at the site of metastasis [55]. Ablation of the FSP-expressing cells, using a thymidine kinase suicide vector system, reduced metastatic potential, reinforcing the role of EMT in metastasis. Conditional induction of MMTV-driven Neu expression allows the reversible formation of primary tumors. Interestingly, frequent $\mathrm{Neu}$ independent relapses are observed in these transgenic mice. Carcinoma cells from these tumors have acquired a mesenchymal phenotype induced by SNAl1 expression [26]. Careful analysis of mouse mammary tumor models shows that 'EMT phenotype tumors', defined as those with dual expression of epithelial and mesenchymal markers, have higher metastatic potential than the spindle-like tumors [54]. This is consistent with an emerging view that EMT may result in hybrid/metastable cells, since increasingly in carcinoma systems, cells coexpressing both epithelial and mesenchymal lineage traits are seen (reviewed in [56]).

Several non-transgenic models of breast cancer have also been used to investigate EMT. Comparative analysis of the transcriptome of tumors derived from four adenocarcinoma mammary cell lines differing in their ability to intravasate, extravasate and metastasize to lung revealed that TWIST expression correlated with the acquisition of the metastatic phenotype and its expression was required to accomplish the full metastatic cascade [57].

\section{Epithelial to mesenchymal transition and breast cancer stem cells}

The BCSC hypothesis suggests that breast cancer is derived from a single tumor initiating cell with stem-like properties [58]. There are two pathways that are thought to give rise to breast carcinoma. The long lived cancer stem cells or the transit-amplifying cells are the targets for carcinogenesis and acquire the capacity to self-renew during the carcinogenesis process. BCSCs are defined as a population of cells with a CD24(-/lo)CD44(+) phenotype. A higher frequency of stem cell-like CD24(-/lo)CD44(+) cells is associated with the basal subtype of breast cancer $[28,40]$. Cancer cells undergoing EMT exhibit stem cell-like characteristics. More recently, metaplastic breast cancers and claudin-low breast cancers have been shown to be enriched for markers of EMT and display stem cell characteristics. However, claudin-low breast cancers are distinct from metaplastic breast cancers as they do not exhibit PIK3CA, AKT or kirsten rat sarcoma viral oncogene homolog (KRAS) mutations [30]. The EMT inducers TGFbeta, SNAI and TWIST confer a stem cell phenotype in immortalized human mammary epithelial cells with increased ability to form mammospheres in threedimensional culture and ductal outgrowths in xenotransplant assays [40,59]. In addition, CD24(-/lo)CD44(+) cells isolated from primary breast carcinoma as well as normal breast show increased expression of EMT-inducing transcription factors (TWIST1, FOXC2, SNAI1, ZEB2 (also known as SIP1) and TWIST2), vimentin and fibronectin compared to CD24(+)CD44(-) epithelial cells isolated from a more differentiated carcinoma do not [40]. Recently, it has also been shown in vivo that CD8 T-cell-mediated immune response to an epithelial breast cancer led to a tumor outgrowth consisting of cells that had undergone EMT. These mesenchymal tumor cells have a CD24(-/lo)CD44(+) phenotype with characteristics of BCSCs, including potent tumorigenicity, ability to re-establish an epithelial tumor, and enhanced resistance to drugs and radiation $[60,61]$.

Cancer cells with stem cell-like characteristics are enriched in residual tumors following standard chemotherapy [62,63]. 
There is a significant increase in the expression of EMTrelated genes in CD24(Io/-)CD44(+) cells from post-treatment biopsies from patients that have received standard anthracycline-taxane chemotherapy compared to patients with ERBB2 positive tumors that have undergone treatment with laptinib, an epidermal growth factor receptor and ERBB2 inhibitor [63].

Normal and transformed mammary epithelial cells that undergo EMT exhibit stem cell properties, including the ability to self-renew and efficiently initiate tumors [40]. This suggests that EMT may facilitate the generation of cancer stem cells with mesenchymal and self-renewal properties required for dissemination and initiation of metastases [64]. While the debate persists over the existence of cancer stem cells (reviewed in [65]), it is clear that this highly malignant subpopulation exhibits features consistent with EMT.

\section{EMT in micrometastasis and disseminated/circulating tumor cells}

Breast carcinoma primary tumors disseminate via the lymph and hematogenous routes. Thus, an essential investigation in patients is the examination of regional lymph for diagnostic purposes. In recent years, the sentinel lymph node technique has been increasingly utilized in an attempt to reduce morbidity linked to surgical removal of auxiliary nodes. Patients with less than $1.7 \mathrm{~cm}$ tumors are eligible for this screening.

Micrometastases in lymph nodes are defined as less than $2 \mathrm{~mm}^{2}$, although rare single cells can also be found. However, the prognostic value of these single cells is not established, since a considerable proportion of these patients do not relapse. Independent of auxiliary lymph node examination, there is an increasing trend to analyze circulating tumor cells (CTCs) in the peripheral blood. The detection of isolated carcinoma cells correlates with a higher risk of relapse. However, the number of cells detected is low, except in locally advanced cancer or in metastatic cancer. The number of CTCs before treatment is an independent predictor of progression-free survival and overall survival in patients with metastatic breast cancer [66].

An assessment of CTCs is an earlier, more reproducible indicator of disease status than current imaging methods. CTCs may be a superior surrogate end point, as they are highly reproducible and correlate better with overall survival than do changes determined by traditional radiology $[67,68]$. Increased sophistication of the methods to isolate, quantify and assess CTCs is allowing more detailed molecular analysis. In a study of 226 patients, Aktas and colleagues [69] found $62 \%$ of CTCs were positive for EMT markers (TWIST, AKT2, or PIK3CA) and 69\% positive for the stem cell marker ALDH1, and that those with EMT and ALDH1 expression were more likely not to respond to therapy.
Although clinically more demanding, the analysis of distant dissemination in the bone marrow reveals the presence of micrometastatic disseminated tumor cells, which have a strong prognostic value. The relative risk associated with disseminated tumor cells was found to be higher than 2 in a large European consortium study including 4,700 breast cancer patients [70]. The relative value of screening blood or bone marrow has been recently reviewed [71] and clearly shows an advantage to bone marrow screening, especially for small tumors. However, the analysis of circulating cells is particularly relevant in the case of neoadjuvant therapy and for post-surgery follow-up in locally advanced carcinoma patients as a means to predict relapses at an earlier stage than is possible with biomarkers and clinical and imaging investigations [71].

Disseminated carcinoma cells residing in the bone marrow are mostly quiescent. It is likely that mechanisms controlling dormancy play a key role in the long-term maintenance of these cells in the bone marrow [72,73]. Disseminated tumor cells were found to be enriched for the CD24(Io/-)CD44(+) phenotype [74]. Moreover, the EMT driver TWIST was found to be over-represented in disseminated tumor cells that persisted in the bone marrow after neoadjuvant chemotherapy, and the presence of TWIST-positive cells in the bone marrow prior to chemotherapy correlated with relapse [75]. In an attempt to assess the clinical relevance of bone marrow micrometastases, bone marrow samples from a large cohort of patients were analyzed according to the different morphological features of cytokeratin-positive cells. This analysis showed that the frequency of bona fide isolated carcinoma cells was lower than in previous reports; however, such cells are detected in patients with low grade tumors of less than $2 \mathrm{~cm}$ [17]. It is noteworthy that sentinel lymph node micrometastases (between 0.2 and $2 \mathrm{~mm}$ ) is not correlated with bone marrow micrometastases (single cells) [76]. These studies provide additional evidence for very early dissemination of isolated tumor cells in the bone marrow [77], and this mechanism operates independently of lymphatic dissemination. The presence of micrometastatic tumor cells in the bone marrow in stage IV breast cancer patients correlates with the presence of bone matrix metastasis and local relapse $[17,78]$.

A critical issue in demonstrating EMT in breast carcinoma has been to show evidence of EMT in the primary tumor leading to isolated invasive cells that could potentially disseminate. These studies have been performed in transgenic models of breast carcinoma driven by the PyMT antigen. Multiphotonic imaging revealed that carcinoma cells dissociate from the primary tumors at sites of interaction with peritumoral macrophages. These single carcinoma cells will eventually be guided toward the neighboring vessels and can be detected throughout their migration and during intravasation. This mechanism is driven by a paracrine loop between perivascular macrophages and tumor cells [79-81]. 
Tumor cells produce CSF1 (colony stimulating factor 1), promoting the recruitment of macrophages that, in turn, produce epithelial growth factor, which acts as a motogen on carcinoma cells. A detailed signaling pathway has been described leading to the formation of lamellipodia through increased expression of Mena, which inhibits actin microfilament capping, N-WASP, which induces ACTR2/3 (actin-related protein 2/3) branched actin formation, and cofilin, a severin protein allowing fast remodeling of actin microfilaments. Mena is detected at the invasive leading edge of tumor cells. Based on these findings, an immunohistochemical pilot study was carried out on tissue sections from patients with non-metastatic breast carcinoma tumor and from patients whose primary cancers eventually metastasized. Using three antibodies to characterize blood vessels (anti-CD31), macrophages (anti-CD68) and migratory cancer cells (anti-Mena), a clear cut correlation was found between the metastatic status and the presence of interacting cancer cells, macrophages and endothelial cells at sites of intravasation [82]. Importantly, this study is one of the first to functionally demonstrate the presence of EMT cells intravasating in blood vessels within primary tumors.

\section{Epithelial to mesenchymal transition and chemotherapeutic resistance}

EMT is implicated in the progression to distant metastatic disease and therapeutic resistance. Studies on NMuMG and $\mathrm{EpH} 4$ murine mammary epithelial cell lines have shown resistance to UV-induced apoptosis following TGFbetainduced EMT [83]. Similarly, downregulation of let-7 miRNA in breast cancer cell lines increases tumor metastasis and therapeutic resistance, and results in stem cell-like characteristics and an EMT-related gene expression profile [62]. It was recently suggested that metaplastic breast cancer and claudin-low tumors, which display EMT and stem cell-like features, may arise from a more chemoresistant breast tumor than basal-like or luminal breast tumors [30].

Chemotherapeutic agents can also enhance the malignancy of carcinoma. Following Adriamycin treatment of MCF7 cells, TWIST1 expression and its interaction with p53-MDM2 is induced and only cells undergoing Adriamycin-induced EMT display enhanced invasion and multidrug resistance. TWIST1 depletion by RNA interference blocked mesenchymal transformation, partially reversed multidrug resistance, and abolished invasion induced by Adriamycin. Furthermore, TWIST1 RNA interference may show efficacy in Adriamycinbased chemotherapies for breast cancer [63].

Resistance to ERBB2 targeted therapy is a clinical problem that may undermine the success of ERBB2 targeted therapies such as trastuzumab and lapatinib. The ERBB2 pathway may play an important role in the maintenance of BCSCs. Induction of EMT in BCSCs may be at the root of resistance of ERBB2 targeted therapy [84]. More generally, breast cancer cells may acquire resistance to conventional and targeted therapies upon conversion to a mesenchymallike phenotype. A recent high throughput screen using transformed human breast cells that were experimentally transformed into mesenchymal cells showed that these cells, which exhibit cancer stem cell properties, are more resistant to conventional chemotherapeutic drugs such as paclitaxel or doxorubicin [85]. Drugs that specifically affect the mesenchymal transformed cells and not the transformed epithelial line were selected. From a screen of 16,000 compounds, several compounds, including salinomycin, were identified to have selective cytotoxity toward enriched breast cancer stem cells. This pioneer study provides a proof of principle that cancer stem cells exhibiting EMT features can be selectively targeted by drugs. However, it is anticipated that even such drugs can induce resistance during treatment. Thus, it is essential that new strategies use combined therapies to interfere with EMT pathways [86].

\section{Conclusion}

This review summarizes evidence for the growing implication of EMT in the progression of breast carcinoma, both in murine models and in humans. However, there is an urgent need for new surrogate markers to define different stages during the transition from the epithelial to mesenchymal phenotype, and the reverse transition. These markers may differ from those expressed by normal-like epithelial cells undergoing EMT. A relevant example is the well described presence of micrometastatic carcinoma cells in the blood and bone marrow that retain cytokeratin expression, and the implication of 'hybrid' cells in several systems. However, capturing the mesenchymal phenotype in primary tumors and metastases may prove to be a difficult task, due to the slow growth kinetics of tumors, resulting in an extended period before a mesenchymal to epithelial transition mechanism occurs. The unique topology of tumor growth in the colon has permitted the observation of rare pioneer isolated carcinomas and their likelihood to reconstitute epithelial-like glandular structures. Preliminary evidence indicates that such cells may exist in primary breast cancer, although their detection would require simultaneous labeling using three antibodies to visualize carcinoma cells in contact with endothelial cells and macrophages.

\section{Competing interests}

The authors declare that they have no competing interests.

\section{References}

1. Chaffer CL, Thompson EW, Williams ED: Mesenchymal to epithelial transition in development and disease. Cells Tissues Organs 2007, 185:7-19.

2. Thiery JP: Epithelial-mesenchymal transitions in tumour progression. Nat Rev Cancer 2002, 2:442-454.

3. Thiery JP: Epithelial-mesenchymal transitions in development and pathologies. Curr Opin Cell Biol 2003, 15:740-746.

4. Elston CW, Ellis IO: Pathological prognostic factors in breast cancer. I. The value of histological grade in breast cancer: experience from a large study with long-term follow-up. Histopathology 1991, 19:403-410.

5. Perou CM, Sørlie T, Eisen MB, van de Rijn M, Jeffrey SS, Rees 
CA, Pollack JR, Ross DT, Johnsen H, Akslen LA, Fluge O, Pergamenschikov A, Williams C, Zhu SX, Lønning PE, Børresen-Dale AL, Brown PO, Botstein D: Molecular portraits of human breast tumours. Nature 2000, 406:747-752.

6. Sørlie T, Perou CM, Tibshirani R, Aas T, Geisler S, Johnsen H, Hastie T, Eisen MB, van de Rijn M, Jeffrey SS, Thorsen T, Quist $H$, Matese JC, Brown PO, Botstein D, Eystein Lønning P, BørresenDale AL: Gene expression patterns of breast carcinomas distinguish tumor subclasses with clinical implications. Proc Natl Acad Sci U S A 2001, 98:10869-10874.

7. Sorlie T, Tibshirani R, Parker J, Hastie T, Marron JS, Nobel A, Deng S, Johnsen H, Pesich R, Geisler S, Demeter J, Perou CM, Lønning PE, Brown PO, Børresen-Dale AL, Botstein D: Repeated observation of breast tumor subtypes in independent gene expression data sets. Proc Natl Acad Sci U S A 2003, 100: 8418-8423.

8. van 't Veer LJ, Dai $H$, van de Vijver MJ, He YD, Hart AA, Mao M, Peterse HL, van der Kooy K, Marton MJ, Witteveen AT, Schreiber GJ, Kerkhoven RM, Roberts C, Linsley PS, Bernards R, Friend $\mathrm{SH}$ : Gene expression profiling predicts clinical outcome of breast cancer. Nature 2002, 415:530-536.

9. Wang Y, Klijn JG, Zhang Y, Sieuwerts AM, Look MP, Yang F, Talantov D, Timmermans M, Meijer-van Gelder ME, Yu J, Jatkoe T, Berns EM, Atkins D, Foekens JA: Gene-expression profiles to predict distant metastasis of lymph-node-negative primary breast cancer. Lancet 2005, 365:671-679.

10. Smid M, Wang Y, Klijn JG, Sieuwerts AM, Zhang Y, Atkins D, Martens JW, Foekens JA: Genes associated with breast cancer metastatic to bone. J Clin Oncol 2006, 24:2261-2267.

11. Smid M, Wang Y, Zhang Y, Sieuwerts AM, Yu J, Klijn JG, Foekens JA, Martens JW: Subtypes of breast cancer show preferential site of relapse. Cancer Res 2008, 68:3108-3114.

12. Rodriguez-Pinilla SM, Sarrio D, Honrado E, Hardisson D, Calero F, Benitez J, Palacios J: Prognostic significance of basal-like phenotype and fascin expression in node-negative invasive breast carcinomas. Clin Cancer Res 2006, 12:1533-1539.

13. Moreno-Bueno G, Portillo F, Cano A: Transcriptional regulation of cell polarity in EMT and cancer. Oncogene 2008, 27:69586969.

14. Polyak K, Weinberg RA: Transitions between epithelial and mesenchymal states: acquisition of malignant and stem cell traits. Nat Rev Cancer 2009, 9:265-273.

15. Barak V, Goike H, Panaretakis KW, Einarsson R: Clinical utility of cytokeratins as tumor markers. Clin Biochem 2004, 37:529540.

16. Teschendorff AE, Journee M, Absil PA, Sepulchre R, Caldas C: Elucidating the altered transcriptional programs in breast cancer using independent component analysis. PLoS Comput Biol 2007, 3:e161.

17. Bidard FC, Vincent-Salomon A, Gomme S, Nos C, de Rycke $Y$, Thiery JP, Sigal-Zafrani B, Mignot L, Sastre-Garau X, Pierga JY: Disseminated tumor cells of breast cancer patients: a strong prognostic factor for distant and local relapse. Clin Cancer Res 2008, 14:3306-3311.

18. Loussouarn D, Campion L, Sagan C, Frenel JS, Dravet F, Classe $J M$, Pioud-Martigny R, Berton-Rigaud D, Bourbouloux E, Mosnier JF, Bataille FR, Campone M.: Prognostic impact of syndecan-1 expression in invasive ductal breast carcinomas. $\mathrm{Br} J$ Cancer 2008, 98:1993-1998

19. Carpenter PM, Wang-Rodriguez J, Chan OT, Wilczynski SP: Laminin 5 expression in metaplastic breast carcinomas. Am J Surg Pathol 2008, 32:345-353.

20. Arima $Y$, Inoue $Y$, Shibata $T$, Hayashi $H$, Nagano $O$, Saya $H$, Taya $\mathrm{Y}$ : $\mathrm{Rb}$ depletion results in deregulation of $\mathrm{E}$-cadherin and induction of cellular phenotypic changes that are characteristic of the epithelial-to-mesenchymal transition. Cancer Res 2008, 68:5104-5112.

21. Ahmad A, Hanby A, Dublin E, Poulsom R, Smith P, Barnes D, Rubens R, Anglard P, Hart I: Stromelysin 3: an independent prognostic factor for relapse-free survival in node-positive breast cancer and demonstration of novel breast carcinoma cell expression. Am J Pathol 1998, 152:721-728.

22. Kasper G, Reule M, Tschirschmann M, Dankert N, Stout-Weider K, Lauster R, Schrock E, Mennerich D, Duda GN, Lehmann KE: Stromelysin-3 over-expression enhances tumourigenesis in MCF-7 and MDA-MB-231 breast cancer cell lines: involvement of the IGF-1 signalling pathway. BMC Cancer 2007, 7:12.
23. Mironchik Y, Winnard PT Jr, Vesuna F, Kato Y, Wildes F, Pathak $A P$, Kominsky $S$, Artemov D, Bhujwalla $Z$, Van Diest $P$, Burger $H$, Glackin C, Raman V: Twist overexpression induces in vivo angiogenesis and correlates with chromosomal instability in breast cancer. Cancer Res 2005, 65:10801-10809.

24. Yang J, Weinberg RA: Epithelial-mesenchymal transition: at the crossroads of development and tumor metastasis. Dev Cell 2008, 14:818-829.

25. Blanco MJ, Moreno-Bueno G, Sarrio D, Locascio A, Cano A, Palacios J, Nieto MA: Correlation of Snail expression with histological grade and lymph node status in breast carcinomas. Oncogene 2002, 21:3241-3246.

26. Moody SE, Perez D, Pan TC, Sarkisian CJ, Portocarrero CP, Sterner CJ, Notorfrancesco KL, Cardiff RD, Chodosh LA: The transcriptional repressor Snail promotes mammary tumor recurrence. Cancer Cell 2005, 8:197-209.

27. Willipinski-Stapelfeldt B, Riethdorf S, Assmann V, Woelfle U, Rau T, Sauter G, Heukeshoven J, Pantel K: Changes in cytoskeletal protein composition indicative of an epithelial-mesenchymal transition in human micrometastatic and primary breast carcinoma cells. Clin Cancer Res 2005, 11:8006-8014.

28. Sarrio D, Rodriguez-Pinilla SM, Hardisson D, Cano A, MorenoBueno G, Palacios J: Epithelial-mesenchymal transition in breast cancer relates to the basal-like phenotype. Cancer Res 2008, 68:989-997.

29. DiMeo TA, Anderson K, Phadke P, Feng C, Perou CM, Naber S, Kuperwasser C: A novel lung metastasis signature links Wnt signaling with cancer cell self-renewal and epithelial-mesenchymal transition in basal-like breast cancer. Cancer Res 2009, 69:5364-5373.

30. Hennessy BT, Gonzalez-Angulo AM, Stemke-Hale K, Gilcrease MZ, Krishnamurthy S, Lee JS, Fridlyand J, Sahin A, Agarwal R, Joy C, Liu W, Stivers D, Baggerly K, Carey M, Lluch A, Monteagudo C, He X, Weigman V, Fan C, Palazzo J, Hortobagyi GN, Nolden LK, Wang NJ, Valero V, Gray JW, Perou CM, Mills GB: Characterization of a naturally occurring breast cancer subset enriched in epithelial-to-mesenchymal transition and stem cell characteristics. Cancer Res 2009, 69:4116-4124.

31. Trimboli AJ, Fukino K, de Bruin A, Wei G, Shen L, Tanner SM, Creasap N, Rosol TJ, Robinson ML, Eng C, Ostrowski MC, Leone G: Direct evidence for epithelial-mesenchymal transitions in breast cancer. Cancer Res 2008, 68:937-945.

32. Vincent-Salomon A, Thiery JP: Host microenvironment in breast cancer development: epithelial-mesenchymal transition in breast cancer development. Breast Cancer Res 2003, 5:101106.

33. Ma XJ, Salunga R, Tuggle JT, Gaudet J, Enright E, McQuary $P$, Payette T, Pistone M, Stecker K, Zhang BM, Zhou YX, Varnholt $\mathrm{H}$, Smith B, Gadd M, Chatfield E, Kessler J, Baer TM, Erlander MG, Sgroi DC: Gene expression profiles of human breast cancer progression. Proc Natl Acad Sci U S A 2003, 100:5974-5979.

34. Vincent-Salomon A, Lucchesi C, Gruel N, Raynal V, Pierron G, Goudefroye R, Reyal F, Radvanyi F, Salmon R, Thiery JP, SastreGarau X, Sigal-Zafrani B, Fourquet A, Delattre O; breast cancer study group of the Institut Curie: Integrated genomic and transcriptomic analysis of ductal carcinoma in situ of the breast. Clin Cancer Res 2008, 14:1956-1965.

35. Osako T, Horii R, Ogiya A, lijima K, Iwase T, Akiyama F: Histogenesis of metaplastic breast carcinoma and axillary nodal metastases. Pathol Int 2009, 59:116-120.

36. Aigner K, Dampier B, Descovich L, Mikula M, Sultan A, Schreiber M, Mikulits W, Brabletz T, Strand D, Obrist P, Sommergruber W, Schweifer N, Wernitznig A, Beug H, Foisner R, Eger A: The transcription factor ZEB1 (deltaEF1) promotes tumour cell dedifferentiation by repressing master regulators of epithelial polarity. Oncogene 2007, 26:6979-6988.

37. Mani SA, Yang J, Brooks M, Schwaninger G, Zhou A, Miura N, Kutok JL, Hartwell K, Richardson AL, Weinberg RA: Mesenchyme Forkhead 1 (FOXC2) plays a key role in metastasis and is associated with aggressive basal-like breast cancers. Proc Natl Acad Sci U S A 2007, 104:10069-10074.

38. Korsching $E$, Packeisen J, Liedtke $C$, Hungermann D, Wulfing $P$ van Diest PJ, Brandt B, Boecker W, Buerger $\mathrm{H}$ : The origin of vimentin expression in invasive breast cancer: epithelial-mesenchymal transition, myoepithelial histogenesis or histogenesis from progenitor cells with bilinear differentiation potential? J Pathol 2005, 206:451-457. 
39. Dumont N, Wilson MB, Crawford YG, Reynolds PA, Sigaroudinia $M$, Tlsty TD: Sustained induction of epithelial to mesenchymal transition activates DNA methylation of genes silenced in basal-like breast cancers. Proc Natl Acad Sci U S A 2008, 105: 14867-14872.

40. Mani SA, Guo W, Liao MJ, Eaton EN, Ayyanan A, Zhou AY, Brooks M, Reinhard F, Zhang CC, Shipitsin M, Campbell LL, Polyak K, Brisken C, Yang J, Weinberg RA: The epithelial-mesenchymal transition generates cells with properties of stem cells. Cell 2008, 133:704-715.

41. Storci G, Sansone P, Trere D, Tavolari S, Taffurelli M, Ceccarelli C, Guarnieri T, Paterini P, Pariali M, Montanaro L, Santini D, Chieco $P$, Bonafé $M$ : The basal-like breast carcinoma phenotype is regulated by SLUG gene expression. J Pathol 2008, 214:25-37.

42. Hill JJ, Tremblay TL, Cantin C, O'Connor-McCourt M, Kelly JF, Lenferink AE: Glycoproteomic analysis of two mouse mammary cell lines during transforming growth factor (TGF)beta induced epithelial to mesenchymal transition. Proteome Sci 2009, 7:2.

43. Safina AF, Varga AE, Bianchi A, Zheng $Q$, Kunnev D, Liang $P$, Bakin AV: Ras alters epithelial-mesenchymal transition in response to TGFbeta by reducing actin fibers and cell-matrix adhesion. Cell Cycle 2009, 8:284-298.

44. Zhou BP, Deng J, Xia W, Xu J, Li YM, Gunduz M, Hung MC: Dual regulation of Snail by GSK-3beta-mediated phosphorylation in control of epithelial-mesenchymal transition. Nat Cell Biol 2004, 6:931-940.

45. Prasad CP, Rath G, Mathur S, Bhatnagar D, Parshad R, Ralhan R: Expression analysis of E-cadherin, Slug and GSK3 beta in invasive ductal carcinoma of breast. BMC Cancer 2009, 9: 325.

46. Gregory PA, Bert AG, Paterson EL, Barry SC, Tsykin A, Farshid G, Vadas MA, Khew-Goodall Y, Goodall GJ: The miR-200 family and miR-205 regulate epithelial to mesenchymal transition by targeting ZEB1 and SIP1. Nat Cell Biol 2008, 10:593-601.

47. Ma L, Teruya-Feldstein J, Weinberg RA: Tumour invasion and metastasis initiated by microRNA-10b in breast cancer. Nature 2007, 449:682-688.

48. Gebeshuber CA, Zatloukal K, Martinez J: miR-29a suppresses tristetraprolin, which is a regulator of epithelial polarity and metastasis. EMBO Rep 2009, 10:400-405.

49. Schoenenberger CA, Andres AC, Groner B, van der Valk M, LeMeur M, Gerlinger P: Targeted c-myc gene expression in mammary glands of transgenic mice induces mammary tumours with constitutive milk protein gene transcription. EMBO J 1988, 7:169-175.

50. Guy CT, Webster MA, Schaller M, Parsons TJ, Cardiff RD, Muller WJ: Expression of the neu protooncogene in the mammary epithelium of transgenic mice induces metastatic disease. Proc Natl Acad Sci U S A 1992, 89:10578-10582.

51. Guy CT, Cardiff RD, Muller WJ: Induction of mammary tumors by expression of polyomavirus middle $\mathrm{T}$ oncogene: a transgenic mouse model for metastatic disease. Mol Cell Biol 1992, 12:954-961.

52. Cardiff RD, Anver MR, Gusterson BA, Hennighausen L, Jensen RA, Merino MJ, Rehm S, Russo J, Tavassoli FA, Wakefield LM, Ward JM, Green JE: The mammary pathology of genetically engineered mice: the consensus report and recommendations from the Annapolis meeting. Oncogene 2000, 19:968988.

53. Rosner A, Miyoshi K, Landesman-Bollag E, Xu X, Seldin DC, Moser AR, MacLeod CL, Shyamala G, Gillgrass AE, Cardiff RD: Pathway pathology: histological differences between ErbB/Ras and Wnt pathway transgenic mammary tumors. Am J Patho/ 2002, 161:1087-1097.

54. Damonte P, Gregg JP, Borowsky AD, Keister BA, Cardiff RD: EMT tumorigenesis in the mouse mammary gland. Lab Invest 2007, 87:1218-1226.

55. Xue C, Plieth D, Venkov C, Xu C, Neilson EG: The gatekeeper effect of epithelial-mesenchymal transition regulates the frequency of breast cancer metastasis. Cancer Res 2003, 63: 3386-3394.

56. Lee JM, Dedhar S, Kalluri R, Thompson EW: The epithelial-mesenchymal transition: new insights in signaling, development, and disease. J Cell Biol 2006, 172:973-981.

57. Yang J, Mani SA, Donaher JL, Ramaswamy S, Itzykson RA, Come
C, Savagner P, Gitelman I, Richardson A, Weinberg RA: Twist, a master regulator of morphogenesis, plays an essential role in tumor metastasis. Cell 2004, 117:927-939.

58. Shackleton M, Vaillant F, Simpson KJ, Stingl J, Smyth GK, AsselinLabat ML, Wu L, Lindeman GJ, Visvader JE: Generation of a functional mammary gland from a single stem cell. Nature 2006, 439:84-88.

59. Morel AP, Lievre M, Thomas C, Hinkal G, Ansieau S, Puisieux A: Generation of breast cancer stem cells through epithelialmesenchymal transition. PLOS ONE 2008, 3:e2888.

60. Sheridan C, Kishimoto H, Fuchs RK, Mehrotra S, Bhat-Nakshatri $\mathrm{P}$, Turner $\mathrm{CH}$, Goulet R Jr, Badve S, Nakshatri H: CD44+/CD24breast cancer cells exhibit enhanced invasive properties: an early step necessary for metastasis. Breast Cancer Res 2006, 8:R59.

61. Santisteban M, Reiman JM, Asiedu MK, Behrens MD, Nassar A, Kalli KR, Haluska P, Ingle JN, Hartmann LC, Manjili MH, Radisky DC, Ferrone S, Knutson KL: Immune-induced epithelial to mesenchymal transition in vivo generates breast cancer stem cells. Cancer Res 2009, 69:2887-2895.

62. Yu F, Yao H, Zhu P, Zhang X, Pan Q, Gong C, Huang Y, Hu X, Su $F$, Lieberman J, Song E: let-7 regulates self renewal and tumorigenicity of breast cancer cells. Cell 2007, 131:11091123.

63. Li QQ, Xu JD, Wang WJ, Cao XX, Chen Q, Tang F, Chen ZQ, Liu $X P, X u Z D$ : Twist1-mediated adriamycin-induced epithelialmesenchymal transition relates to multidrug resistance and invasive potential in breast cancer cells. Clin Cancer Res 2009, 15:2657-2665

64. Hollier BG, Evans K, Mani SA: The epithelial-to-mesenchymal transition and cancer stem cells: a coalition against cancer therapies. J Mammary Gland Biol Neoplasia 2009, 14:29-43.

65. Rosen JM, Jordan CT: The increasing complexity of the cancer stem cell paradigm. Science 2009, 324:1670-1673.

66. Cristofanilli M, Budd GT, Ellis MJ, Stopeck A, Matera J, Miller MC, Reuben JM, Doyle GV, Allard WJ, Terstappen LW, Hayes DF: Circulating tumor cells, disease progression, and survival in metastatic breast cancer. N Engl J Med 2004, 351:781-791.

67. Budd GT, Cristofanilli M, Ellis MJ, Stopeck A, Borden E, Miller MC, Matera J, Repollet M, Doyle GV, Terstappen LW, Hayes DF: Circulating tumor cells versus imaging - predicting overall survival in metastatic breast cancer. Clin Cancer Res 2006, 12:6403-6409.

68. Hayes DF, Smerage J: Is there a role for circulating tumor cells in the management of breast cancer? Clin Cancer Res 2008, 14:3646-3650.

69. Aktas B, Tewes M, Fehm T, Hauch S, Kimmig R, Kasimir-Bauer S: Stem cell and epithelial-mesenchymal transition markers are frequently over-expressed in circulating tumor cells of metastatic breast cancer patients. Breast Cancer Res 2009, 11:R46.

70. Braun S, Vogl FD, Naume B, Janni W, Osborne MP, Coombes RC, Schlimok G, Diel IJ, Gerber B, Gebauer G, Pierga JY, Marth C, Oruzio D, Wiedswang G, Solomayer EF, Kundt G, Strobl B, Fehm T, Wong GY, Bliss J, Vincent-Salomon A, Pantel K: A pooled analysis of bone marrow micrometastasis in breast cancer. N Engl J Med 2005, 353:793-802.

71. Fehm T, Muller V, Alix-Panabieres C, Pantel K: Micrometastatic spread in breast cancer: detection, molecular characterization and clinical relevance. Breast Cancer Res 2008, 10(Suppl 1): S1.

72. Alix-Panabieres $\mathrm{C}$, Riethdorf $\mathrm{S}$, Pantel K: Circulating tumor cells and bone marrow micrometastasis. Clin Cancer Res 2008, 14: 5013-5021.

73. Pantel K, Brakenhoff $\mathrm{RH}$, Brandt B: Detection, clinical relevance and specific biological properties of disseminating tumour cells. Nat Rev Cancer 2008, 8:329-340.

74. Balic M, Lin H, Young L, Hawes D, Giuliano A, McNamara G, Datar RH, Cote RJ: Most early disseminated cancer cells detected in bone marrow of breast cancer patients have a putative breast cancer stem cell phenotype. Clin Cancer Res 2006, 12:5615-5621.

75. Watson MA, Ylagan LR, Trinkaus KM, Gillanders WE, Naughton $\mathrm{MJ}$, Weilbaecher KN, Fleming TP, Aft RL: Isolation and molecular profiling of bone marrow micrometastases identifies TWIST1 as a marker of early tumor relapse in breast cancer patients. Clin Cancer Res 2007, 13:5001-5009. 
76. Vincent-Salomon A, Caly M, De Rycke $Y$, Fréneaux P, Klijanienko $J$, Laé M, Viard F, Nos C, Bidard FC, Alran S, Salmon R, Kirova Y, Pierga JY, Sigal-Zafrani B, Sastre-Garau X: Lobular phenotype related to occult-metastatic spread in axillary sentinel node and/or bone marrow in breast carcinoma. Eur $J$ Cancer 2009.45:1979-1986

77. Hüsemann $Y$, Geigl JB, Schubert $F$, Musiani $P$, Meyer $M$, Burghart E, Forni G, Eils R, Fehm T, Riethmüller G, Klein CA: Systemic spread is an early step in breast cancer. Cancer Cell 2008, 13: 58-68.

78. Bidard FC, Vincent-Salomon A, Sigal-Zafrani B, Dieras V, Mathiot C, Mignot L, Thiery JP, Sastre-Garau X, Pierga JY: Prognosis of women with stage IV breast cancer depends on detection of circulating tumor cells rather than disseminated tumor cells. Ann Oncol 2008, 19:496-500.

79. Wyckoff J, Wang W, Lin EY, Wang Y, Pixley F, Stanley ER, Graf T, Pollard JW, Segall J, Condeelis J: A paracrine loop between tumor cells and macrophages is required for tumor cell migration in mammary tumors. Cancer Res 2004, 64:70227029.

80. Condeelis J, Segall JE: Intravital imaging of cell movement in tumours. Nat Rev Cancer 2003, 3:921-930.

81. Condeelis J, Pollard JW: Macrophages: obligate partners for tumor cell migration, invasion, and metastasis. Cell 2006, 124 : 263-266.

82. Robinson BD, Sica GL, Liu YF, Rohan TE, Gertler FB, Condeelis JS, Jones JG: Tumor microenvironment of metastasis in human breast carcinoma: a potential prognostic marker linked to hematogenous dissemination. Clin Cancer Res 2009, 15:2433-2441.

83. Robson EJ, Khaled WT, Abell K, Watson CJ: Epithelial-to-mesenchymal transition confers resistance to apoptosis in three murine mammary epithelial cell lines. Differentiation 2006, 74: 254-264.

84. Bedard PL, de Azambuja E, Cardoso F: Beyond trastuzumab: overcoming resistance to targeted HER-2 therapy in breast cancer. Curr Cancer Drug Targets 2009, 9:148-162.

85. Gupta PB, Onder TT, Jiang G, Tao K, Kuperwasser C, Weinberg RA, Lander ES: Identification of selective inhibitors of cancer stem cells by high-throughput screening. Cell 2009, 138:645659.

86. Chua KN, Ma XJ, Thiery JP: Targeted therapies in control of EMT in carcinoma and fibrosis. Drug Discovery Today 2008, 4: 261-267

87. Friedl $\mathrm{P}$, Gilmour $\mathrm{D}$ : Collective cell migration in morphogenesis, regeneration and cancer. Nat Rev Mol Cell Biol 2009, 10: 445-457.

88. Lien HC, Hsiao YH, Lin YS, Yao YT, Juan HF, Kuo WH, Hung MC, Chang KJ, Hsieh FJ: Molecular signatures of metaplastic carcinoma of the breast by large-scale transcriptional profiling: identification of genes potentially related to epithelial-mesenchymal transition. Oncogene 2007, 26:7859-7871. 